\title{
Downregulation of esophageal cancer-related gene 4 promotes proliferation and migration of hepatocellular carcinoma
}

\author{
SHUJIAN GE ${ }^{1}$, YALI XU ${ }^{2}$, HONGLIANG WANG ${ }^{3}$, YAXIN SUN $^{3}$, XIANGGUO TIAN $^{4}$, \\ ZHIXIN CAO ${ }^{2}$, XIAOYAN LIN $^{2}$, JIAWEN XU ${ }^{2}$ and QIANGXIU WANG ${ }^{2}$
}

Departments of ${ }^{1}$ Science and Education, and ${ }^{2}$ Pathology, Shandong Provincial Hospital Affiliated to Shandong University, Jinan, Shandong 250021; ${ }^{3}$ Shandong Academy of Occupational Health and Occupational Medicine, Jinan, Shandong 250062;

${ }^{4}$ Department of Gastroenterology, Shandong Provincial Hospital Affiliated to Shandong University,

Jinan, Shandong 250021, P.R. China

Received October 15, 2015; Accepted March 21, 2017

DOI: $10.3892 / \mathrm{ol} .2017 .6616$

\begin{abstract}
Esophageal cancer-related gene 4 (ECRG4) is a candidate tumor suppressor gene, which is involved in cell apoptosis, migration, infection and inflammation responsiveness; however, its expression level and clinical significance in hepatocellular carcinoma (HCC) remains unclear. In the present study, the authors aim to evaluate the clinical significance and potential role of ECRG4 in HCC. Level of ECRG4 protein expression in HCC and peripheral tissues was investigated in tissue specimens obtained from 56 consecutive HCC patients by immunohistochemistry. Cell proliferation, cell migration and invasion regulations were examined by MTT curves, flow cytometry, Transwell assays and western blotting. ECRG4 expression was weak positive in normal liver cells but was downregulated in $\mathrm{HCC}$ cells in vivo or in vitro. A decreased expression of ECRG4 was associated with the age of the patients, metastasis and Ki-67 proliferation index. However, decreased ECRG4 expression was not associated with differentiation, tumor size, the presence of portal vein tumor thrombosis, satellite lesions, tumor relapse or mortality. Further investigations revealed that ectopic expression of ECRG4 inhibited cell proliferation, migration and invasion and promoted cell apoptosis in SMMC-7721 cells, which was mediated by the regulation of BAX and B cell lymphoma-2, in addition to the upregulation of epithelial-mesenchymal transition markers. In conclusion, the results of the present study indicated that ECRG4 was downregulated in HCC and served important roles in promoting cell proliferation and migration.
\end{abstract}

Correspondence to: Professor Qiangxiu Wang, Department of Pathology, Shandong Provincial Hospital Affiliated to Shandong University, 324 Weiqi Avenue, Jingwu Road, Jinan, Shandong 250021, P.R. China

E-mail: wangqiangxiu@163.com

Key words: esophageal cancer-related gene 4, hepatocellular carcinoma, immunohistochemistry, western blotting

\section{Introduction}

Hepatocellular carcinoma (HCC) is one of the most common malignant tumors, with the third highest tumor-associated mortality rate worldwide (1). Given that the majority of patients with HCC are in the terminal stage of the disease when diagnosed, numerous strategies, including surgical exeresis, transarterial chemoembolization and liver transplantation cannot not be applied (2). Consequently, this leads to reduced survival time due to high proliferation rate and migration ability of HCC (3).

Esophageal cancer-related gene 4 (ECRG4) was first clonally identified as an esophageal cancer-associated tumor suppressor gene in 1998 (4). The ECRG4 gene is 12,500 base pairs (bp) in length and is localized on chromosome 2ql2.2. The 444 bp open reading frame of ECRG4 comprises four exons that encode a 148-amino acid peptide named ECRG4 protein with a size of $17 \mathrm{\kappa Da}$. ECRG4 is widely expressed in normal tissues, including the heart, brain, lung, liver, placenta, skeletal muscle, pancreas, kidney and prostate (5). In recent years, ECRG4 expression, which serves a crucial role in the progression of the malignant biological phenotype, has reported to be suppressed in esophageal squamous, breast, colorectal cancers and neurogliocytoma (6-9). However, few studies have reported ECRG4 expression in HCC. The present study aimed to investigate ECRG4 expression levels in HCC in patient samples and in HCC cell lines. Furthermore, the roles of ECRG4 in HCC initiation and progression as well as its underlying mechanism were examined.

\section{Materials and methods}

Patients and samples. Pathological samples from 56 patients with HCC were collected during radical surgery from the Department of Hepatobiliary Surgery, Shandong Provincial Hospital (Jinan, China) from January 2008 to December 2010. Of the 56 patients, 42 were male and 14 were female, with a median age of 55.68 years (range, 35-77 years). All patient samples were histologically graded according to the World Health Organization Classification of Tumors (10). The major clinicopathological parameters are presented in 
Table I. The tumors were graded into three types according to their degree of differentiation; well-differentiated, moderately differentiated and poorly differentiated. The number of patients for each tumor type were 8, 31 and 17, respectively. Normal hepatic tissues distant from tumor tissues that had no hepatic cirrhosis, adenoma or focal nodular hyperplasia were also obtained. Tumor staging was performed according to the recommendations of the International Union Against Cancer (11). None of the patients received any treatment prior to surgery, including radiotherapy or chemotherapy. Follow-up sessions were performed on all of the patients and the median follow-up duration was 43.4 \pm 3.61 months after the patients who succumbed to the disease were excluded. Written informed consent was obtained from all patients prior to enrollment in the present study. The use of the tissue specimens was approved by the Research Ethics Committee of Shandong Medical University (Jinan, Shandong).

Immunohistochemical procedures and evaluation. Immunohistochemical Envision method was performed on tissues sections (thickness, $4 \mu \mathrm{m}$ ) cut from formalin-fixed, paraffin-embedded blocks. The samples were deparaffinized in xylene and rehydrated through a graded series of ethanol washes. Following inhibition of the endogenous peroxidase and antigen retrieval using microwave irradiation in $0.01 \mathrm{M}$ citrate buffer at $\mathrm{pH}$ 6.0), the tissue sections were blocked with a $3 \% \mathrm{H}_{2} \mathrm{O}_{2}$-methanol solution for $10 \mathrm{~min}$ at room temperature and then incubated with primary antibodies at $4{ }^{\circ} \mathrm{C}$ overnight, and then with horseradish peroxidase (HRP)-conjugated secondary antibodies (Dako; Agilent Technologies, Inc., Santa Clara, CA, USA) for $4 \mathrm{~min}$ at $4^{\circ} \mathrm{C}$. All cases were investigated for the presence of a rabbit polyclonal antibody against ECRG4 (cat. no., sc-135139; 1:100; Santa Cruz Biotechnology, Inc., Dallas, TX, USA) and a monoclonal antibody against Ki-67 (cat. no., 9449; 1:500; Cell Signaling Technology, Inc., Danvers, MA, USA). Subsequent to washing, sections were stained with 3,30-diaminobenzidine (DAB) chromogen for 5 min and counterstained with hematoxylin (Zhongshan Golden Bridge, Inc.) at room temperature, then dehydrated and coverslips placed on top of the samples. Colon carcinoma tissues were used for the positive controls, and the negative control sections were incubated with PBS instead of the primary antibody.

The immunostaining results were examined independently by two clinical pathologists of the Department of Pathology, Shandong Provincial Hospital using a light microscope (Scope.A1; Carl Zeiss AG, Oberkochen, Germany) at a magnification of $\mathrm{x} 400$. For ECRG4, the results were classified as negative (score 0), weak (score 1-3), moderate (score 4-6) and intense (score 7-9), based on the percentage of positive cells and staining intensity by multiplying the two scores. To specify, a sample was scored 0-3 according to the percentage of positive cells $(0,0 \% ; 1,1-10 \% ; 2,11-50 \% ; 3,51-100 \%)$ and the staining intensity $(0$, negative; 1 , light brown; 2 , moderate brown; 3, dark brown). All cases were divided into two groups: Low (score 0 or $1+$ ) and high $(2+$ or $3+$ ) expression. The Ki67 labeling index was scored by counting 500 cells and evaluating the percentage of cells that stained positively in the nucleus: Score 1, 0-10\%; score 2, 10-30\%; score 3, 30-70\%; score $4,>70 \%$. For the evaluation of ECRG4 expression level, a score of 1 or 2 were considered as the low expression, whereas scores of 3 or 4 were classified as high expression.

Cell culture. SMMC-7721, HepG2, BEL-7404 and L02 cell lines were purchased from the Type Culture Collection of the Chinese Academy of Sciences (Shanghai, China). All cell lines were cultured in RPMI-1640 (Gibco; Thermo Fisher Scientific, Inc., Waltham, MA, USA) supplemented with $10 \%$ fetal bovine serum (PAA Laboratories; GE Healthcare Life Sciences, Chalfont, UK), $100 \mathrm{U} / \mathrm{ml}$ penicillin and $100 \mu \mathrm{g} / \mathrm{ml}$ streptomycin (Gibco; Thermo Fisher Scientific, Inc.). The cells were cultured at $37^{\circ} \mathrm{C}$ in a humidified atmosphere containing $5 \% \mathrm{CO}_{2}$.

Plasmid transfection. SMMC-7721 cells were transfected with recombinant eukaryotic expression vector pcDNA3.1-ECRG4 (purchased from Transheep Biotech, Shanghai, China) or pcDNA3.1 vector using Lipofectamine ${ }^{\mathrm{TM}} 2000$ (Invitrogen; Thermo Fisher Scientific, Inc.), according to the manufacturer's protocol: The cells were grown to $60 \%$ confluence in a 6 -well dish prior to plasmid transfection, $4 \mu \mathrm{g}$ plasmid DNA and $10 \mu$ l Lipofectamine 2000 complexes were added in $2 \mathrm{ml}$ of Opti-MEM medium (Gibco; Thermo Fisher Scientific, Inc.). Following a $6 \mathrm{~h}$ incubation at $37^{\circ} \mathrm{C}$, culture medium was changed to usual complete medium, and the cells were subsequently cultured at $37^{\circ} \mathrm{C}$ for another $42 \mathrm{~h}$ until harvested.

Protein extraction and western blot analysis. The cells were collected and lysed in modified radioimmunoprecipitation assay buffer (Beyotime Institute of Biotechnology, Haimen, China), supplemented with Complete Protease Inhibitor Cocktail (1 tablet/50 ml; Roche Molecular Diagnostics, Pleasanton, CA, USA). Total cell lysate (50 $\mu \mathrm{g}$ protein) was resolved by $10 \%$ SDS-PAGE and electrophoretically transferred onto polyvinylidene fluoride (PVDF) membranes (EMD Millipore, Billerica, MA, USA). Following blocking in 5\% non-fat milk for $40 \mathrm{~min}$ at room temperature, PVDF membranes were incubated overnight with primary antibodies against ECRG4 (cat. no., sc-135139, 1:1,000; Santa Cruz Biotechnology, Inc.), $\beta$-actin (cat. no., A1978, 1:2,000; Sigma-Aldrich; Merck KGaA, Darmstadt, Germany), Bax (cat. no., 2774, 1:1,000; Cell Signaling Technology, Inc.), B cell lymphoma-2 (cat. no., 2872, Bcl-2; 1:1,000; Cell Signaling Technology, Inc.), E-cadherin (cat. no., 3195, 1:1,000; Cell Signaling Technology, Inc.), N-cadherin (cat. no., 13116, 1:1,000; Cell Signaling Technology, Inc.) and Snail (cat. no., 3879, 1:1,000; Cell Signaling Technology, Inc.) at $4^{\circ} \mathrm{C}$, respectively. Subsequently, the membranes were incubated for $1 \mathrm{~h}$ at $4^{\circ} \mathrm{C}$ with the appropriate horseradish peroxidase-conjugated goat anti-mouse IgG (cat.no., 31430) and goat anti-rabbit IgG (H+L, cat. no., 31460, Invitrogen; Thermo Fisher Scientific, Inc.) secondary antibodies. Specific protein bands were detected by enzyme-linked chemiluminescence kit (ECL; Pierce; Thermo Fisher Scientific, Inc.) and protein concentration was estimated relative to $\beta$-actin using Quantity one $^{\circledR}$ 1-D software (Bio-Rad Laboratories, Inc., Hercules, CA, USA).

Cell proliferation assay. Cell proliferation was determined using a modified MTT assay (Roche Applied Science, Penzberg, Germany). Transfected and control cells ( $7 \times 10^{3}$ cells/well) were seeded into 96-well plates. Following 1-7 days culture 
Table I. Association of ECRG4 expression level with clinicopathological factors $(n=56)$.

\begin{tabular}{|c|c|c|c|c|c|}
\hline & \multirow[b]{2}{*}{ Total $(n=56)$} & \multicolumn{2}{|c|}{ ECRG4 expression level } & \multirow[b]{2}{*}{$\chi^{2}$} & \multirow[b]{2}{*}{ P-value } \\
\hline & & Low $(n=49)$ & High $(n=7)$ & & \\
\hline Age at surgery (years) & & & & 7.439 & $0.024^{\mathrm{a}}$ \\
\hline$\leq 35$ & 1 & 0 & 1 & & \\
\hline $36-50$ & 13 & 11 & 2 & & \\
\hline$\geq 51$ & 42 & 38 & 4 & & \\
\hline Differentiation & & & & 1.828 & 0.401 \\
\hline Well & 17 & 16 & 1 & & \\
\hline Moderately & 31 & 27 & 4 & & \\
\hline Poorly & 8 & 6 & 2 & & \\
\hline Tumor size & & & & 0.280 & 0.870 \\
\hline$<2 \mathrm{~cm}$ & 6 & 5 & 1 & & \\
\hline $2-5 \mathrm{~cm}$ & 21 & 18 & 3 & & \\
\hline$>5 \mathrm{~cm}$ & 29 & 26 & 3 & & \\
\hline PVTT & & & & 1.377 & 0.241 \\
\hline Absent & 37 & 31 & 6 & & \\
\hline Present & 19 & 18 & 1 & & \\
\hline Metastasis & & & & 4.800 & $0.028^{\mathrm{a}}$ \\
\hline Absent & 35 & 28 & 7 & & \\
\hline Present & 21 & 21 & 0 & & \\
\hline Satellite lesions & & & & 1.956 & 0.162 \\
\hline Absent & 45 & 38 & 7 & & \\
\hline Present & 11 & 11 & 0 & & \\
\hline Cirrhosis & & & & 0.242 & 0.622 \\
\hline Absent & 12 & 11 & 1 & & \\
\hline Present & 44 & 38 & 6 & & \\
\hline Progression & & & & 0.369 & 0.543 \\
\hline Absent & 26 & 22 & 4 & & \\
\hline Present & 30 & 27 & 3 & & \\
\hline Mortality & & & & 3.046 & 0.081 \\
\hline Absent & 23 & 18 & 5 & & \\
\hline Present & 33 & 31 & 2 & & \\
\hline Ki67 status & & & & 6.383 & $0.012^{\mathrm{a}}$ \\
\hline Low & 17 & 12 & 5 & & \\
\hline High & 39 & 37 & 2 & & \\
\hline
\end{tabular}

${ }^{\text {a }}<<0.05$. ECRG4, esophageal cancer-related gene 4; PVTT, portal vein tumor thrombosis.

with $5 \% \mathrm{CO}_{2}, 20 \mu 11 \mathrm{mg} / \mathrm{ml}$ MTT was added to each well and incubated for a further $4 \mathrm{~h}$ at $37^{\circ} \mathrm{C}$, and was subsequently replaced with $150 \mu \mathrm{l}$ dimethyl sulfoxide for $10 \mathrm{~min}$ at $37^{\circ} \mathrm{C}$. Absorbance was determined at $490 \mathrm{~nm}$ using an ELISA multi-well spectrophotometer (Molecular Devices, LLC, Sunnyvale, CA, USA). Each group contained 6 wells, and the experiments were repeated three times.

Flow cytometry for cell apoptosis detection. A total of $5 \times 10^{4}$ SMMC-7721 human hepatocellular carcinoma cells were cultured in RPMI-1640 supplemented with $10 \%$ fetal bovine serum in $5 \% \mathrm{CO}_{2}$ at $37^{\circ} \mathrm{C}$. The SMMC-7721 cells were then transfected with pcDNA3.1-ECRG4 constructs as aforementioned. Following a $48 \mathrm{~h}$ incubation at $37^{\circ} \mathrm{C}$, the cells were collected by adding $0.25 \%$ pancreatic enzyme at room temperature for $1 \mathrm{~min}$ and then $1 \mathrm{ml}$ cold phosphate buffered solution at room temperature for $1 \mathrm{~min}$. Subsequently, the cells were transferred to $1.5 \mathrm{ml}$ cold Eppendorf microcentrifuge tubes and centrifuged at $4^{\circ} \mathrm{C}$ for $5 \mathrm{~min}$ at $600 \mathrm{x}$ g. The supernatant was then discarded, and the cells were resuspended in $1 \mathrm{ml}$ cold $70 \%$ ethanol. The cells were stored overnight at $-20^{\circ} \mathrm{C}$. Flow cytometry was subsequently performed to detect cell apoptosis. The un-transfected SMMC-7721 cells were used as the control. All the protocols were performed repeated in triplicate. 
Table II. Log-rank test of overall survival time of patients with hepatocellular carcinoma.

A, Mean survival time

$95 \% \mathrm{CI}$

\begin{tabular}{lcccc}
\cline { 4 - 4 } ECRG4 expression level & Average & SE & Lower & Upper \\
\hline Low & 47.231 & 4.197 & 39.005 & 55.458 \\
High & 60.000 & 6.636 & 46.993 & 73.007 \\
Total & 49.796 & 3.932 & 42.089 & 57.503 \\
\hline
\end{tabular}

B, Median survival time

\begin{tabular}{lcccc}
\hline Low & 45.000 & 6.999 & 31.283 & 58.717 \\
High & - & - & - & - \\
Total & 48.000 & 9.759 & 28.872 & 67.128 \\
\hline
\end{tabular}

Log-rank test, $\chi^{2}=2.431 ; \mathrm{P}=0.119$. ECRG4, esophageal cancer-related gene 4; SE, standard error; CI, confidence interval.

Transwell invasion and migration assays. Cell invasion ability was evaluated in Boyden dual chambers with $8 \mu \mathrm{m}$ pore size membranes (BD Biosciences, Franklin Lakes, NJ, USA). The membranes were coated with $40 \mu$ l Matrigel (BD Biosciences) for $4 \mathrm{~h}$ at $37^{\circ} \mathrm{C}$. A density of $2 \times 10^{4}$ cells were suspended in $0.7 \mathrm{ml}$ serum-free media (Gibco; Thermo Fisher Scientific, Inc.) and added to the upper chamber, and the lower chamber contained serum-positive media as a chemoattractant. Following incubation for $48 \mathrm{~h}$ at $37^{\circ} \mathrm{C}$ with $5 \% \mathrm{CO}_{2}$, the media and cells remaining in the upper chamber were removed using a cotton swab. The insert was fixed in $75 \%$ methanol and stained with hematoxylin and eosin for $5 \mathrm{~min}$ at room temperature. The number of invading cells was counted in five random high-power fields (magnification, $x 400$ ) using the inverted microscope (Nikon Eclipse TE300, Tokyo, Japan) and the mean number of invading cells was evaluated for analysis. The procedure of cell migration assays followed the aforementioned steps, with the exception of not adding Matrigel to the membranes. For each assay, three identical replicates were performed.

Statistical analysis. Statistics were calculated by SPSS software v.19 (IBM SPSS, Armonk, NY, USA). All data are presented as the mean \pm standard error of the mean. The differences were analyzed by using the ANOVA, Student's t-test, as appropriate. Dunnett's-test was used to compare the migration and invasion abilities. Kaplan-Meier survival analysis was used to estimate the prognostic relevance of ECRG4 and the survival difference between groups was assessed by the log-rank test. $\mathrm{P}<0.05$ was considered to indicate a statistically significant difference.

\section{Results}

ECRG4 expression level in HCC samples and cell lines. Immunohistochemistry was performed to evaluate ECRG4 expression level in $56 \mathrm{HCC}$ samples and normal hepatic tissues. Moderate to strong positive ECRG4 expression was detected in the majority of the normal hepatic tissues, with only 2 samples revealing weak positive expression. By contrast, ECRG4 expression was significantly downregulated in HCC tissues compared with normal hepatic tissues. Of the 56 HCC tissue samples, 7 samples demonstrated high expression levels, which was reduced compared with normal hepatic tissues (Fig. 1; $\mathrm{P}<0.01$ ).

Furthermore, western blot analysis was performed to assess ECRG4 protein expression levels in HCC and normal hepatic cell lines. The HepG2, SMMC-7721, and BEL-7404 human HCC cell lines exhibited lower ECRG4 expression levels compared with the L02 normal hepatic cell line (Fig. 2). These results were consistent with the immunohistochemistry results in patient samples.

Association of ECRG4 expression level with clinicopathologic parameters. As presented in Table I, there was no significant association between levels of ECRG4 expression and histological degree of differentiation, tumor size, presence of portal vein tumor thrombosis, satellite lesions, tumor relapse or mortality rate $(\mathrm{P}>0.05)$. However, there were significant negative associations between levels of ECRG4 expression and age, metastasis and Ki-67 proliferation index $(\mathrm{P}<0.05$; Table I).

Log-rank test results demonstrated that the overall survival rate was significantly higher in the high ECRG4 expression level group compared with in the low ECRG4 expression level group (Table II). Kaplan-Meier survival curves also revealed the overall survival time of the low ECRG4 expression group was much shorter compared with the high ECRG4 expression group (Fig. 3). However, the difference between the two groups was not statistically significant due to the small number of the samples enrolled in the present study $(\mathrm{P}>0.05)$.

Elevated ECRG4 may inhibit HCC cell proliferation and promote apoptosis. In order to determine whether ECRG4 affects HCC cell growth, ECRG4 expression was upregulated by constructing a pcDNA3.1-ECRG4 overexpression plasmid and transfecting the construct into SMMC-7721 cells. Cell 
A

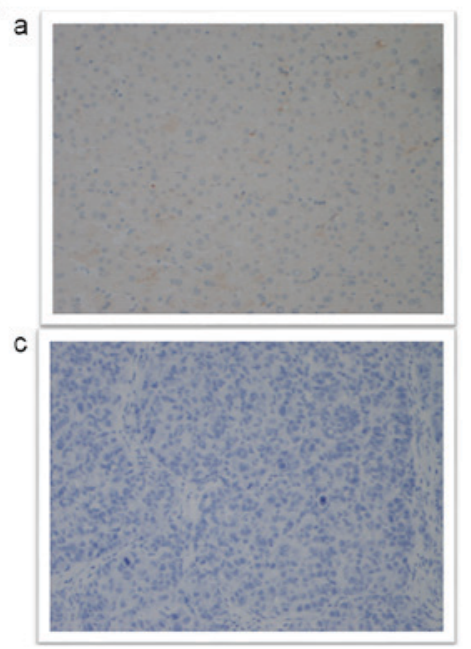

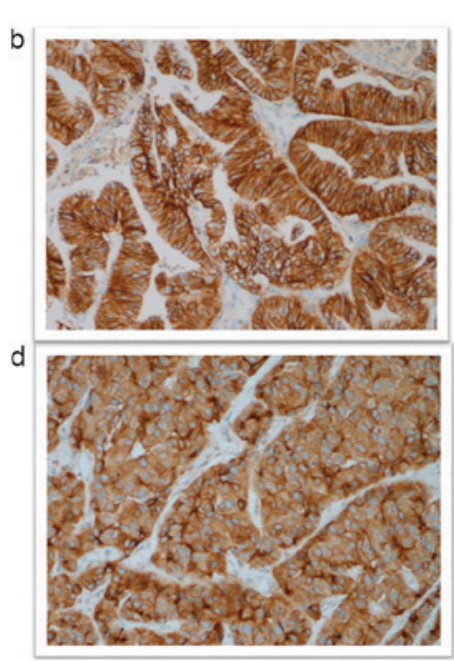

B

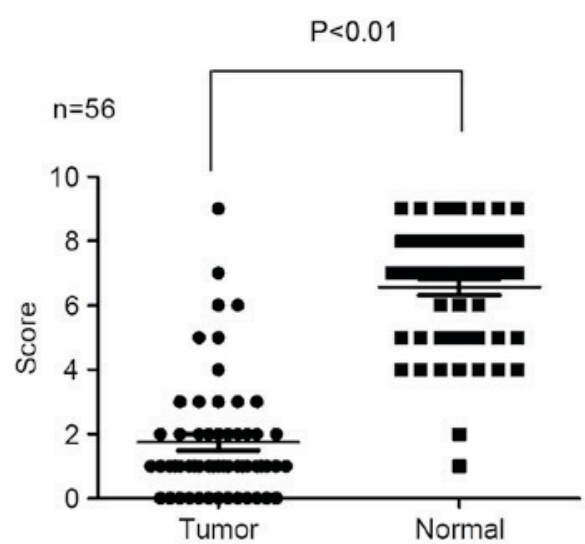

Figure 1. ECRG4 immunostaining. (A) Representative images of tissue sections stained for ECRG4. (Panel a) In normal liver tissue, negative staining was detected in the cytoplasm or membranes with weak staining; (panel b) in colon cancer tissues, positive staining was detected in the cytoplasm and membranes with moderate to strong staining; (panel c) negative staining of ECRG4 in HCC tissues; (panel d) positive staining of ECRG4 in HCC tissues. Magnification, x400 in all cases. (B) The expression level of ECRG4 in 56 pairs of HCC and corresponding noncancerous liver tissue samples were detected by immunostaining. The results demonstrated that the expression level of ECRG4 in HCC tissue samples was lower compared with normal liver tissue samples. ECRG4, esophageal cancer-related gene 4; HCC, hepatocellular carcinoma.

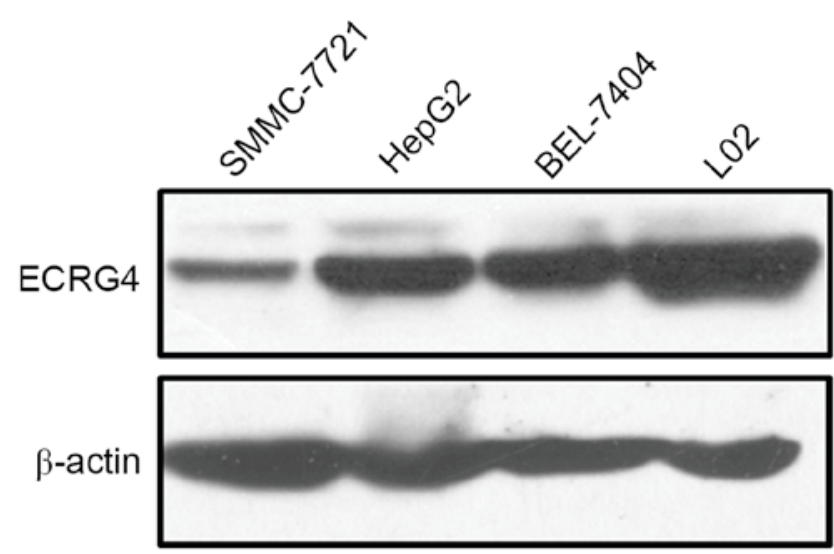

Figure 2. ECRG4 expression level was determined by western blotting. $\beta$-actin served as the control for sample loading. All fields are representative of multiple fields observed in $\geq 3$ independent experiments. ECRG4, esophageal cancer-related gene 4 .

proliferation and apoptosis was determined using MTT assays and flow cytometry, respectively. Compared with the non-transfected cells, the proliferation rate was decreased $(\mathrm{P}<0.05$; Fig. 4A), and the apoptotic rate was significantly increased in SMMC-7721 cells transfected with the pcDNA3.1-ECRG4 plasmid ( $\mathrm{P}<0.05$; Fig. 4B).

The mitochondria signaling pathway is a classical cell apoptosis pathway (12). Western blotting was used to investigate the potential mechanisms underlying ECRG4 in the induction of apoptosis of SMMC-7721 cells. Western blotting revealed that when ECRG4 expression was upregulated, BAX expression level decreased. By contrast, Bcl-2 expression level was increased, which may effectively promote apoptosis in SMMC-7721 cells (Fig. 4C).

Upregulation of ECRG4 may increase migration ability of HCC. A Transwell chamber assay was used to

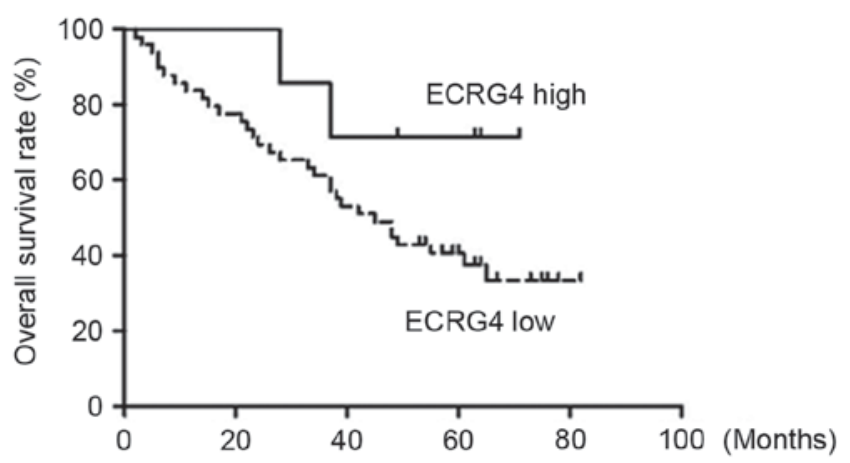

Figure 3. Kaplan-Meier plot of overall survival of 56 patients with HCC stratified by ECRG4 expression level. ECRG4, esophageal cancer-related gene 4.

investigate the role of ECRG4 in HCC metastasis. The number of SMMC-7721-ECRG4+ cells that invaded into the Matrigel filter membrane (or without Matrigel) was significantly decreased compared with the control (Fig. 5), suggesting that upregulation of ECRG4 may effectively inhibit the migration ability of HCC cells.

ECRG4 may affect the migration ability of HCC cells by reversing epithelial-mesenchymal transition (EMT). EMT is one of the most important factors in promoting tumor cell migration, which serves a key role in the development of an organism and participates in tissue healing and oncogenesis (13). To explore the potential mechanism underlying the effect of ECRG4 on HCC cells migration ability, ECRG4 expression was upregulated in SMMC-7721 cells by transfecting pcDNA3.1-ECRG4 plasmid constructs. Western blot analysis was performed to determine the changes in EMT-associated phenotypic markers E-cadherin and N-cadherin (Fig. 6). The results demonstrated that E-cadherin expression levels were increased in the pcDNA3.1-ECRG4-transfected SMMC-7721 
A

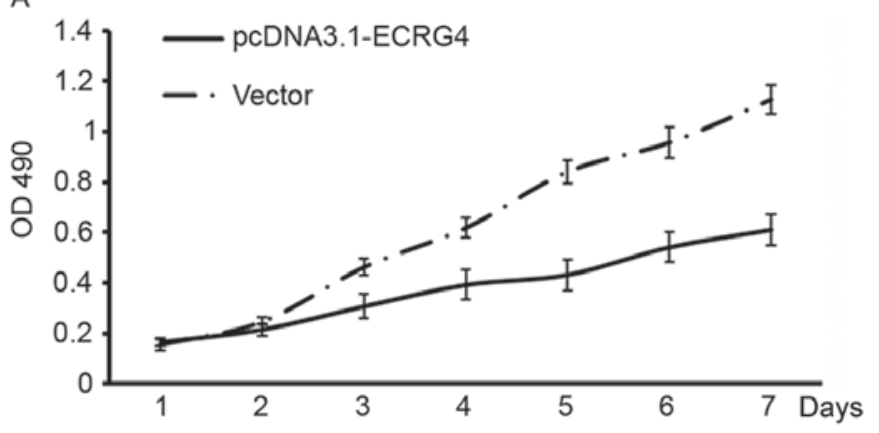

B

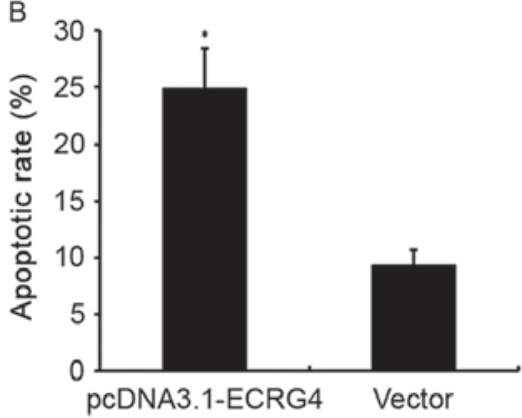

C

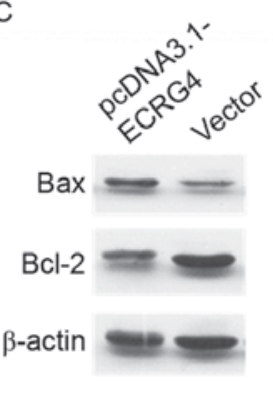

Figure 4. Effects of ECRG4 expression on proliferation of SMMC-7721. SMMC-7721 cells were transfected with pcDNA3.1-ECRG4 plasmid. (A) Cell growth curve determined by MTT assay. Each point indicates the mean spectrometric absorbance \pm standard error of the mean of three independent experiments (B) Cell apoptotic ratio analyzed by flow cytometry. Each bar indicates the mean of cell apoptosis \pm standard error of the mean of three independent experiments. ${ }^{~} \mathrm{P}<0.05$ vs. vector control. (C) BAX and Bcl-2 protein expression levels evaluated by western blot analysis. $\beta$-actin served as the control for sample loading. OD, optical density; Bcl-2, b cell lymphoma-2; ECRG4, esophageal cancer-related gene 4.

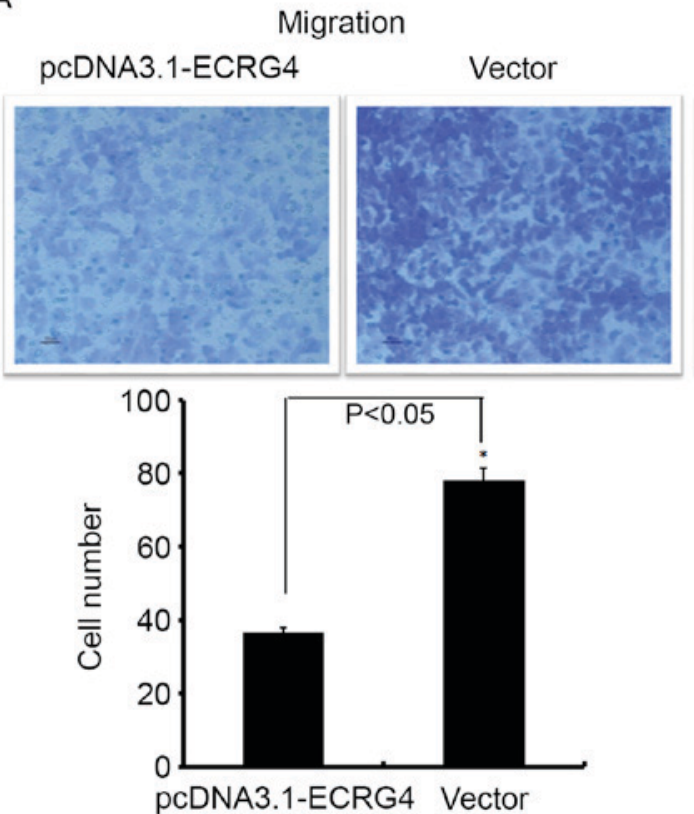

B pcDNA3.1-ECRG4 Invasion Vector
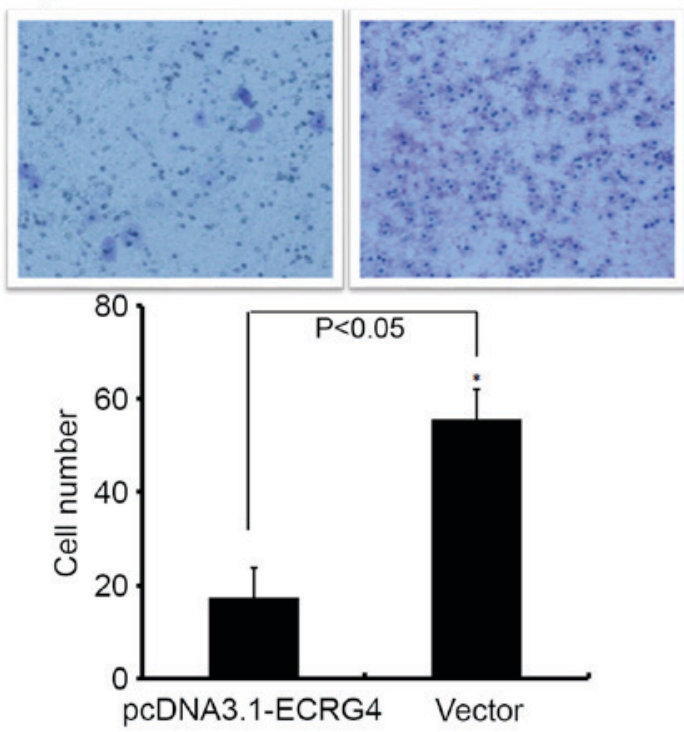

Figure 5. Effects of ECRG4 expression on invasion and migration of SMMC-7721 cells. (A) Migration and (B) invasion ability of cells in the ECRG4 plasmid transfection and vector control groups were evaluated by Transwell chamber assays. The bar graphs present the average number of cells invaded or migrated for each experimental group in 5 fields. Magnification, $\mathrm{x} 400$ in all cases. Statistical analysis was performed with Dunnett's-test. * $\mathrm{P}<0.05$. ECRG4, esophageal cancer-related gene 4 .

cells compared with the cells transfected with the vector alone. These findings indicate that ECRG4 may affect HCC cell migration ability by reversing EMT.

\section{Discussion}

HCC is one of the most common malignant types of tumor worldwide (14). Given that effective measures for early discovery and diagnosis are lacking, most patients with HCC are diagnosed at the end stage of the disease, resulting in high mortality rates (15). Therefore, the development of a biomarker for HCC diagnosis and prognosis is urgently required.

ECRG4 (C2ORF40; GenBank accession no. 325503) was first identified as a differentially expressed gene through comparison of normal esophageal tissues and familial esophageal cancer tissues by the Cancer Research Institute of Chinese Academy of Medical Sciences (4). The downregulation of ECRG4 expression in esophageal cancer tissues indicated that it may be a candidate tumor suppressor gene $(16,17)$. Thereafter, more studies demonstrated that ECRG4 was involved in the initiation and progression of numerous types of cancer, including breast carcinoma, squamous cell carcinoma of the head and neck, gastric cancer and neurogliocytoma $(6,18-20)$. In particular, low ECRG4 expression level was reported to significantly promote tumor cell migration and inhibit apoptosis $(9,17,21)$. The present study investigated ECRG4 expression level in HCC. To the best of our knowledge, the present study is the first to investigate the underlying mechanisms of ECRG4 in HCC cell proliferation and migration. 


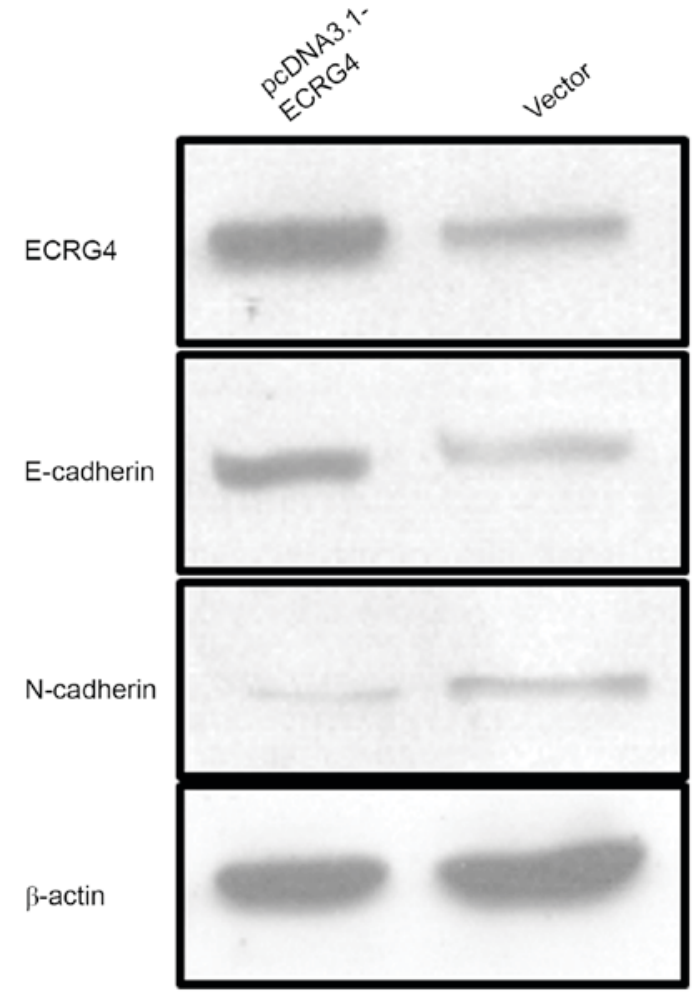

Figure 6. Protein expression levels of ECRG4, E-cadherin and N-cadherin. The protein expression levels were determined by western blot analysis. $\beta$-actin served as the control for sample loading. ECRG4, esophageal cancer-related gene 4 .

A total of $56 \mathrm{HCC}$ patient samples were used in the present study. Of note, in 49 of the HCC tissue samples, ECRG4 expression was low or even undetectable. By contrast, ECRG4 expression in normal hepatic tissues was positive in all cases. Similar levels of ECRG4 expression were demonstrated in the SMMC-7721, HepG2, BEL-7404 HCC cell lines compared with the L02 normal hepatic cell line. Although there was no statistically significant associations between the levels of ECRG4 expression and histological degree of differentiation, tumor sizes, presence of presence of portal vein tumor thrombosis and satellite lesions, downregulated ECRG4 expression was significantly associated with older age and tumor metastasis. These findings indicate that ECRG4 may affect tumor migration as well as invasion. Ki-67 expression, a nuclear marker of cell proliferation, was associated with a poorer outcome in predication of prognosis of patients with HCC (22). The present study demonstrated that HCC tissue samples with decreased ECRG4 expression were more likely to express high Ki-67 expression levels, suggesting that ECRG4 depletion may serve important roles in acquiring biological malignant potential in HCC. Sabatier et al (6) observed a similar phenomenon in patients with breast cancer, they revealed that ECRG4 was overexpressed in smaller, early-stage tumors and significantly underexpressed in later-stage tumors or positive sentinel lymph node status. Furthermore, downregulated ECRG4 expression was closely associated with poorer overall survival and disease-free survival (6). The survival analysis of the present study also demonstrated that the 5-year survival rate in patients underexpressing ECRG4 was lower compared with patients with high levels of ECRG4 expression (36.7 vs. 71.4\%).
However, the number of patients enrolled in the present study was insufficient to obtain statistical significance. Future studies involving a larger group of patients are required to validate the prognostic efficacy of ECRG4 and reveal its pathophysiologic relevance in $\mathrm{HCC}$.

A previous study by Xu et al (15) reported that upregulation of ECRG4 in M2 cells, a head and neck squamous carcinoma cell line, resulted in a significant decrease in proliferation rate. To determine whether ECRG4 serves a similar role in the proliferation of HCC cells, ECRG4 expression was upregulated in SMMC-7721 cells by transfecting with pcDNA-3.1-ECRG4 plasmids to observe alterations in proliferation and apoptosis. Upregulation of ECRG4 inhibited SMMC-7721 cell proliferation and increased the rate of apoptosis. Furthermore, the present study observed a significant change in the $\mathrm{Bax} / \mathrm{Bcl}-2$ ratio, suggesting that ECRG4 may induce cell apoptosis by activating a mitochondria-dependent apoptosis pathway via Bax/Bcl-2 changes. Another ECRG4-induced apoptosis pathway reported in neurogliocytoma indicated that other pathways, including the nuclear factor- $\kappa b$ signaling pathway, were also involved in ECRG4-induced apoptosis (19).

Promotion of tumor cell migration ability is the initiating factor for tumor migration, invasion and metastasis. The Transwell chamber analysis of the present study indicated that overexpressed ECRG4 resulted in a decrease in SMMC-7721 cell migration ability. This finding partially explained the observation in patient samples that those with low ECRG4 expression were more vulnerable to metastasis. EMT is a biological process during which epithelial cells transform into mesenchymal cells. This transition is important in multiple physiological and pathological processes, including embryonic development, tissue reconstruction and tumor metastasis $(23,24)$. Notably, high expression levels of E-cadherin (an epithelial biomarker) and decreased expression levels of $\mathrm{N}$-cadherin (a mesenchymal biomarker), were observed in SMMC-7721 cells with overexpressed ECRG4. These findings indicated that ECRG4 may inhibit tumor migration and metastasis by reversing EMT.

In conclusion, the present study investigated ECRG4 expression level in HCC tissue samples and cell lines. The present study demonstrated that the downregulation of ECRG4 expression may induce inhibition of apoptosis and promote migration, which participated in the oncogenesis, development and metastasis of HCC. Although marked differences of 5-year survival rates between patients with high and low ECRG4 expression levels were observed, the sample size was too small to obtain statistical significance. Consequently, the conclusion that ECRG4 is an independent prognostic factor for 5-year survival rates was not drawn. However, ECRG4 is a candidate clinical biomarker for patients with HCC. Therefore, an intensive investigation into the biological mechanisms of ECRG4 in HCC should be performed in the future.

\section{Acknowledgements}

The present study was supported by the National Nature Science Foundation for Young Scientists of China (grant no. 81202092), the Key and Development Program of 
Shandong Province (grant no. 2015GSF118015) and the China Postdoctoral Science Foundation (grant no. 2015M572053).

\section{References}

1. Bruix J, Gores GJ and Mazzaferro V: Hepatocellular carcinoma: Clinical frontiers and perspectives. Gut 63: 844-855, 2014.

2. Akoad ME and Pomfret EA: Surgical resection and liver transplantation for hepatocellular carcinoma. Clin Liver Dis 19 381-399, 2015.

3. Mlynarsky L, Menachem Y and Shibolet O: Treatment of hepatocellular carcinoma: Steps forward but still a long way to go. World J Hepatol 7: 566-574, 2015.

4. Su T, Liu H and Lu S: Cloning and identification of cDNA fragments related to human esophageal cancer. Zhonghua Zhong Liu Za Zhi 20: 254-257, 1998 (In Chinese).

5. Matsuzaki J, Torigoe T, Hirohashi Y, Tamura Y, Asanuma H, Nakazawa E, Saka E, Yasuda K, Takahashi S and Sato N: Expression of ECRG4 is associated with lower proliferative potential of esophageal cancer cells. Pathol Int 63: 391-397, 2013.

6. Sabatier R, Finetti P, Adelaide J, Guille A, Borg JP, Chaffanet M, Lane L, Birnbaum D and Bertucci F: Down-regulation of ECRG4, a candidate tumor suppressor gene, in human breast cancer. PLoS One 6: e27656, 2011.

7. Wang YB and Ba CF: Promoter methylation of esophageal cancer-related gene 4 in gastric cancer tissue and its clinical significance. Hepatogastroenterology 59: 1696-1698, 2012.

8. Matsuzaki J, Torigoe T, Hirohashi Y, Kamiguchi K, Tamura Y, Tsukahara T, Kubo T, Takahashi A, Nakazawa E, Saka E, et al: ECRG4 is a negative regulator of caspase-8-mediated apoptosis in human T-leukemia cells. Carcinogenesis 33: 996-1003, 2012.

9. Götze S, Feldhaus V, Traska T, Wolter M, Reifenberger G, Tannapfel A, Kuhnen C, Martin D, Müller O and Sievers S: ECRG4 is a candidate tumor suppressor gene frequently hypermethylated in colorectal carcinoma and glioma. BMC Cancer 9: 447, 2009.

10. Bosman FT, Carneiro F, Hruban RH and Theise ND (eds): World Health Organization Classification of Tumours of the Digestive System. Vol. 3. 4th edition. IARC Press, Lyon, 2010.

11. Xu HB, Xu LZ, Li L, Fu J and Mao XP: Reversion of P-glycoprotein-mediated multidrug resistance by guggulsterone in multidrug-resistant human cancer cell lines. Eur J Pharmacol 694: 39-44, 2012.

12. Weinberg SE and Chandel NS: Targeting mitochondria metabolism for cancer therapy. Nat Chem Biol 11: 9-15, 2015.

13. Lu Z, Jiao D, Qiao J, Yang S, Yan M, Cui S and Liu Z: Restin suppressed epithelial-mesenchymal transition and tumor metastasis in breast cancer cells through upregulating mir-200a/b expression via association with p73. Mol Cancer 14: 102, 2015
14. Hu F, Deng X, Yang X, Jin H, Gu D, Lv X, Wang C, Zhang Y, Huo X, Shen Q, et al: Hypoxia upregulates Rab11-family interacting protein 4 through HIF-1 $\alpha$ to promote the metastasis of hepatocellular carcinoma. Oncogene 34: 6007-6017, 2015.

15. Liu H, Li P,Zhai Y, Qu CF, Zhang LJ, Tan YF, Li N and Ding HG Diagnostic value of glypican-3 in serum and liver for primary hepatocellular carcinoma. World J Gastroenterol 16: 4410-4415, 2010.

16. Mori Y, Ishiguro H, Kuwabara Y, Kimura M, Mitsui A, Kurehara H, Mori R, Tomoda K, Ogawa R, Katada T, et al: Expression of ECRG4 is an independent prognostic factor for poor survival in patients with esophageal squamous cell carcinoma. Oncol Rep 18: 981-985, 2007.

17. Li L, Zhang C, Li X, Lu S and Zhou Y: The candidate tumor suppressor gene ECRG4 inhibits cancer cells migration and invasion in esophageal carcinoma. J Exp Clin Cancer Res 29: 133, 2010.

18. Jiang CP, Wu BH, Wang BQ, Fu MY, Yang M, Zhou Y and Liu F: Overexpression of ECRG4 enhances chemosensitivity to 5-fluorouracil in the human gastric cancer SGC-7901 cell line. Tumour Biol 34: 2269-2273, 2013

19. Li W, Liu X, Zhang B, Qi D, Zhang L, Jin Y and Yang H: Overexpression of candidate tumor suppressor ECRG4 inhibits glioma proliferation and invasion. J Exp Clin Cancer Res 29: 89, 2010.

20. Xu T, Xiao D and Zhang X: ECRG4 inhibits growth and invasiveness of squamous cell carcinoma of the head and neck in vitro and in vivo. Oncol Lett 5: 1921-1926, 2013.

21. Jia J, Dai S, Sun X, Sang Y, Xu Z, Zhang J, Cui X, Song J and Guo X: A preliminary study of the effect of ECRG4 overexpression on the proliferation and apoptosis of human laryngeal cancer cells and the underlying mechanisms. Mol Med Rep 12: 5058-5064, 2015

22. Chen HW, Huang XD, Li HC, He S, Ni RZ, Chen CH, Peng C, Wu G, Wang GH, Wang YY, et al: Expression of FOXJ1 in hepatocellular carcinoma: Correlation with patients' prognosis and tumor cell proliferation. Mol Carcinog 52: 647-659, 2013.

23. Huang JY, Zhang K, Chen DQ, Chen J, Feng B, Song H, Chen Y, Zhu Z, Lu L, De W, et al: MicroRNA-451: Epithelial-mesenchymal transition inhibitor and prognostic biomarker of hepatocelluar carcinoma. Oncotarget 6: 18613-18630, 2015.

24. Luo Y, He DL, Jiang YG, Ning L, Shen SL, Zhao JH and Cui XH: Role of beta-catenin signaling pathway in EMT of human prostate cancer induced by HIF-lalpha. Zhonghua Yi Xue Za Zhi 90: 1131-1136, 2010 (In Chinese). 